\title{
Middle ear pathologies in adults within the mining industry: A systematic review
}

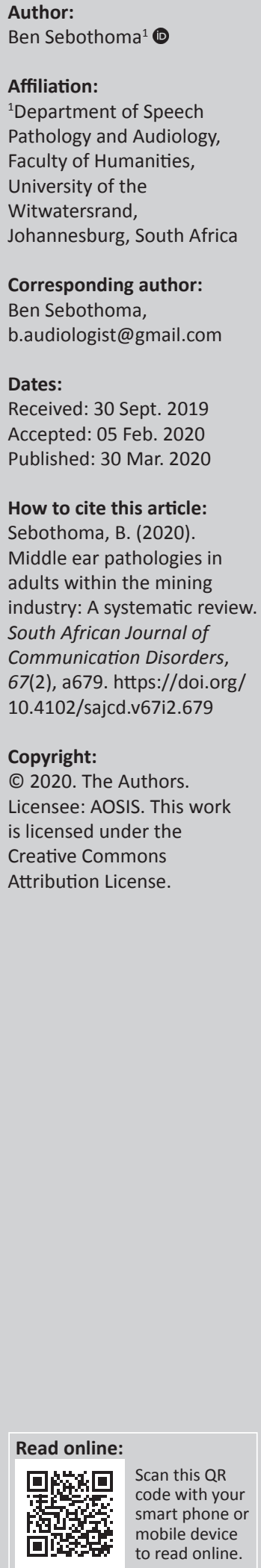

Background: Literature suggests that risk factors for middle ear pathologies, such as traumatic injuries and human immunodeficiency virus (HIV), exist in mines. However, studies on hearing health in mines seem to focus primarily on occupational noise-induced hearing loss and ignore middle ear pathologies. As a result, there is little documented evidence on the trends of middle ear pathologies in mine workers.

Objectives: The aim of this study was to explore and document published evidence reflecting trends in middle ear pathologies in mine workers.

Method: A systematic literature review of studies that reported middle ear pathologies in mine workers was conducted. Medline, CINAHL, PubMed, PsychInfo and Google Scholar databases were searched for studies in English published between January 1994 and December 2018 and reporting on trends in middle ear pathologies in mine workers.

Results: Two research studies met the selection criteria and were included for analysis. One research study used tympanometry with $226 \mathrm{~Hz}$ probe tone, while another study used interviews to determine the presence of middle ear pathologies. While these studies indicate that middle ear pathologies exist in individuals working in mines, the evidence is limited.

Conclusion: While current data indicate that individuals working in mines may present with middle ear pathologies of varying severities, the evidence is too small to provide a clear trend of middle ear pathologies in individuals working in mines. Therefore, the current limited data suggest a need for further studies to examine middle ear pathologies in individuals working in mines.

Keywords: Middle ear pathologies; Mining industries; Systematic review; Adults; Trends.

\section{Introduction}

Although the mining industry plays an important role in the economic growth of any country, especially African countries, health hazardous conditions such as the auditory pathologies continue to be the biggest threats to this growth (Cawood, 2011). Consequently, the Mine Health and Safety Council (MHSC) of South Africa in 2003, which was revised in 2014, called for urgent action to prevent and manage auditory pathologies. However, the occupational noise-induced hearing loss (ONIHL) became the central focus in the literature, with little or no focus on middle ear pathologies (Amedofu, 2002; Chadambuka, Mususa, \& Muteti, 2013; Kanji, Khoza-Shanagse, \& Ntlhakana, 2019; Moroe \& Khoza-Shangase, 2018; Musiba, 2015).

According to the World Health Organization (WHO), middle ear pathologies are amongst the most common auditory pathologies affecting over 700 million people worldwide (WHO, 2018). Although middle ear pathologies can be treated with simple antibiotics (Vouloumanou et al., 2009), the prolongation of middle ear pathologies can cause complications. According to WHO (2018), over 30 million people with acute otitis media (AOM) will develop chronic suppurative otitis media (CSOM), of which approximately 50\% will develop permanent hearing loss. Kolo, Salisu, Yaro and Nwaorgu (2012) also found an association between CSOM and sensorineural hearing loss (SNHL). In addition, middle ear pathologies have also been linked with auditory processing difficulties (Villa \& Zachetta, 2014). and intracranial complications (Sharma, Jaiswal, Barnerjee, \& Garg, 2015).

Given the trends of middle ear pathologies across the world, it is plausible that these pathologies also exist in mines. Furthermore, literature has reported that risk factors associated with middle ear

Note: Special Collection: Occupational Hearing Loss in Africa. 
pathologies exist in mines. Donoghue (2004) reviewed occupational health hazards in mining and found that human immunodeficiency virus (HIV) and minor traumatic injuries were key amongst the health hazards. Hermanus (2007) argued that the existence of HIV in mining can be attributed to the living and working conditions of the miners. The United States Agency for International Development (USAID) also reported that the conditions of the mines may contribute to the risky sexual activities engaged by mine workers as a coping mechanism (Martins-Fonteyn et al., 2017).

Numerous studies have found an association between HIV and middle ear pathologies (Ensink \& Kuper, 2017; Matas, Angrisani, Magliaro, \& Segurado, 2014; Obasineke, Amdi, Ibekwe, Ezeanolue, \& Ogisi, 2014; Sebothoma \& KhozaShangase, 2018; Tshifularo, Govender, \& Monama, 2013; Vajpayee, Negi, \& Kurapati, 2013). These studies suggest that HIV incapacitates the immune system, making it ineffective to fight the invading pathogens. Consequently, middle ear pathologies occur from the opportunistic infections (Vajpayee, Negi, \& Kurapati, 2013). The prevalence of middle ear pathologies in individuals living with HIV can be as high as $60 \%$ (Matas et al., 2014).

On the contrary, MØller (2006) argued that traumatic injury to the ear can interrupt the ossicular chain, reduce the sound energy into the ear and cause conductive hearing loss (CHL). In a prospective analytical study conducted by Sogebi, Oyewole and Mabifah (2018), 47.8\% of the 205 participants with various forms of ear trauma presented with tympanic membrane perforation. Of these, $20.8 \%$ of the ear trauma were categorised to be accidental or self-inflicting injuries. Arguably, these accidental injuries may relate to the one described by Donoghue (2004) in the review. While sound reduction appears to be an immediate consequence of impaired middle ear system (MØller, 2006), non-pulsatile tinnitus and vertigo are also found to be associated with traumatic injuries of the middle ear (Delrue et al., 2016). These conditions can have a significant impact on individuals' day-to-day living and affect the quality of life (Anderson, Parbery-Clark, White-Schwoch, Drehobl, \& Kraus, 2013; Holman, Drummond, Hughes, \& Naylor, 2019).

In light of the risk factors for middle ear pathologies that are reported to exist in mines, and the common trends of middle ear pathologies, the present study aimed to explore and document, through a systematic review, published evidences reflecting trends in middle ear pathologies in mine workers.

\section{Methods \\ Data sources and literature search}

This systematic literature review was conducted in line with the Cochrane collaboration guidelines in conjunction with the Preferred Reporting Items for Systematic Reviews and Meta-Analysis (PRISMA) (Moher et al., 2009). A comprehensive search was conducted on articles that had reported on middle ear pathologies in mine workers.
A computer-aided search of online journal databases, including Medline, CINAHL, PubMed, PsychInfo and Google Scholar, was undertaken. The following keywords were used: 'middle ear pathologies' OR 'middle ear disorders' OR 'middle ear infection' OR 'ear infection' OR 'otitis media' OR 'conductive hearing loss' OR 'hearing loss' OR 'hearing impairment' OR 'ear trauma' OR 'ossicular disorder' AND 'work-related' AND 'mining' OR mineworkers.

\section{Inclusion criteria}

The search was conducted on articles published between January 1994 and December 2018. This time frame was similar to the one used in another systematic review on mining workers and ONIHL (Moroe, Khoza-Shangase, Kanji, \& Ntlhakana, 2018). Studies were included in this review if they were published in peer-reviewed journals, included mine workers and documented their middle ear status. Furthermore, studies had to be written in English. Studies were also included even if they were not randomised controlled trial (RCT) studies (Higgins \& Altman, 2011).

\section{Data extraction and synthesis}

A total of 4494 titles were retrived. Of these, 12 studies were removed as these were duplicates. As a result, 4482 studies were considered and screened. Of the 4482, 4458 studies were excluded based on the titles and/or abstracts because they were not in line with the present study. A total of 24 articles were assessed for eligibility, but 22 studies were exlcuded with reasons (e.g. studies did not measure middle ear function). Finally, a total of 2 studies were included for analysis. The PRISMA flow diagram, showing the process of selecting studies for inclusion in this review is included (Figure 1).

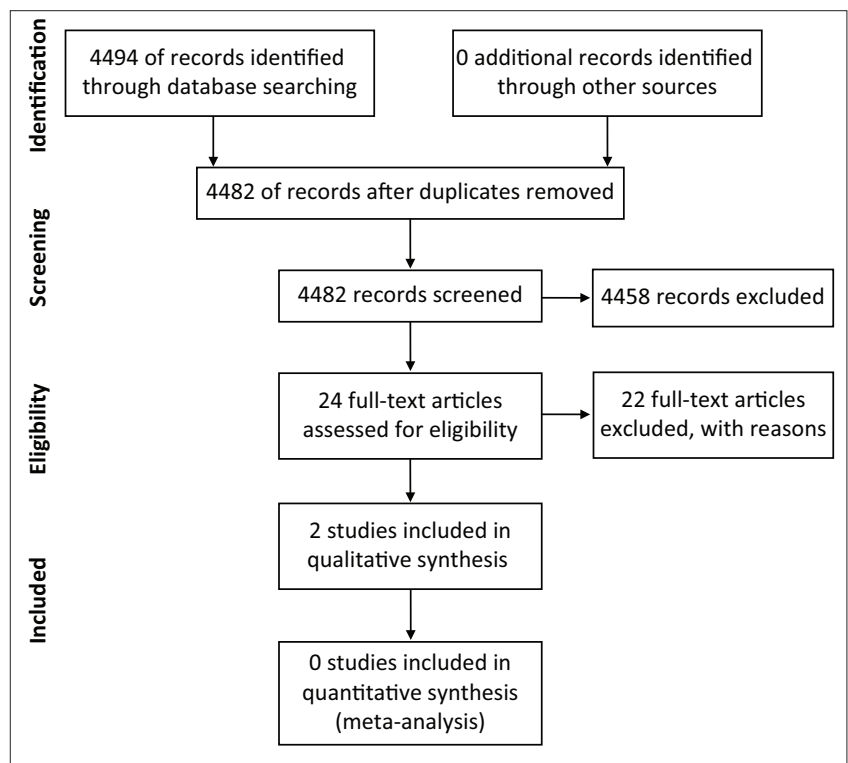

Source: Adapted from Djulbegovic, M., Beyth, R.J., Neberger, M.M., Stoffs, T.L., Vieweg, J., Djulbegovic, B., \& Dahm, P. (2010). Screening for prostate cancer: Systematic review and meta-analysis of randomised controlled trials, British Medical Journal, 341, c4543. https:// doi.org/10.1136/bmj.c4543

FIGURE 1: The Preferred Reporting Items for Systematic Reviews and MetaAnalysis flow diagram describing the inclusion of studies. 


\section{Ethical considerations}

This article followed all ethical standards for a research without direct contact with human or animal subjects.

\section{Results}

Table 1 summarises the results identified for the review through literature search. A total of 4494 studies were retrieved from all four databases. Of these studies, 4470 were excluded as they did not meet the selection criteria and 24 records were selected based on their titles and/or abstract. Of the 24 selected records, 22 were excluded because of duplication and the fact that they did not report on middle ear status of individuals working in mines. Finally, two research articles met the criteria for analysis. Table 2 summarises the studies included for analysis.

\section{Measure of middle ear assessment}

This review identified two research studies that had used different measures to determine the presence of middle ear pathologies in individuals working in mines. Landen, Wilkins, Stephenson \& McWilliams, (2004) examined the middle ear status of the miners using tympanometry with $226 \mathrm{~Hz}$ probe tone. The cut-off values of tympanometry used in this study was adopted from the criteria described by Margolis and Shanks (1985). Saunders et al. (2013), on the contrary, used an interview method to determine whether participants presented with middle ear problems. Participants in this study were asked to indicate whether they have or had a history of ear discharge (otorrhoea).

\section{Rates of middle ear pathologies}

One research study that used tympanometry with $226 \mathrm{~Hz}$ probe tone (Landen et al., 2004) reported that $6.4 \%(n=19)$ of the participants recruited from the sand and gravel mine presented with some form of abnormal tympanometry. However, the types of abnormal tympanograms (e.g. type A) were not reported. These participants were ultimately excluded from the main study because the primary purpose of the study was to examine inner ear hearing loss. However, for the purpose of this review, this number $(n=19)$ was included for analysis. The study by Saunders et al. (2013), who used interview methods to determine the presence of middle ear pathologies, reported that $14 \%$ of the participants reported

TABLE 1: Summary of research studies identified through database search.

\begin{tabular}{lc}
\hline Databases & Hits \\
\hline Medline & 1659 \\
CINAHL & 2176 \\
PubMed & 511 \\
Psychlnfo & 145 \\
\hline
\end{tabular}

prior ear drainage (otorrhoea). In this study, only ear drainage was enquired about. Other middle ear-related symptoms, such as aural fullness, itchiness and otalgia, were not reported.

\section{Discussion}

The aim of this systematic review was to summarise evidence reflecting trends in middle ear pathologies in individuals working in mines. Specifically, this systematic review aimed to look at the rates of middle ear pathologies, middle ear measures used, severity and risk factors. To the author's knowledge, this is the first systematic review that explored and documented middle ear pathologies in individuals working in mines. Because of the heterogeneity of the studies included in this review, only qualitative synthesis was conducted.

This systematic review identified two research studies that reported on middle ear pathologies in individuals working in mines. These studies reported that middle ear pathologies exist (Landen et al., 2004; Saunders et al., 2013), perhaps in varying severities. For example, Saunders et al. (2013) reported that their study participants presented with otorrhoea. MØller (2006) indicated that otorrhoea is often consistent with advanced form of middle ear pathologies, such as chronic otitis media with effusion. However, because otoscope and tympanometry results were not reported, it is difficult to determine the nature of the middle ear pathologies.

Given that individuals working in mines are susceptible to traumatic injuries, and have been shown to have high prevalence of HIV (Hermanus, 2007), it is surprising and concerning that middle ear pathologies in this population are largely ignored. Baltazar et al. (2015) reported that the conditions of the mines may contribute to the risky sexual acitiviies engaged by mine workers. Tuan (2010) found that miners engage in risky sexual behaviours as a coping mechanism. Baltazar et al. (2015) also reported that $22.3 \%$ of Mozambicans working in South African mines were living with HIV. Of those, approximately $75 \%$ of the participants did not know their HIV status. This means that the majority of participants (75\%) were not on HIV treatment, making them even more prone to middle ear pathologies (Obasineke et al., 2014; Van der Westhuizen, Swanepoel, Heinze, \& Hofmeyr, 2013).

The findings of this systematic review suggest that hearing conservation programmes (HCPs) need to include middle ear assessment. This may provide a better management and quality of life of individuals working in mines. The author suspects partly that the paucity of evidence of this important auditory information may be because of lack of involvement of audiologists in mines, as highlighted by Moroe and KhozaShanagse (2018).

TABLE 2: Middle ear pathologies in mine workers.

\begin{tabular}{llll}
\hline Study & Sample size & Middle ear measure & Findings \\
\hline Landen et al. (2004) & $n=294$ & $226 \mathrm{~Hz}$ tymp & $6.4 \%$ presented with abnormal tympanometry \\
Saunders et al. (2013) & $n=59$ & Interview & $14 \%$ reported prior ear drainage
\end{tabular}




\section{Conclusion}

This is the first systematic review to look at the trends of middle ear pathologies in adults working in mines. However, this review highlights the paucity of research in the area of middle ear pathologies in individuals working in mines. There were only two research studies that reported on middle ear pathologies in adults working in mines. While these studies indicate that middle ear pathologies exist in adults working in mines, evidence is too small and weak to suggest any trends. Therefore, the findings of this review suggest that there is a need for assessment of middle ear pathologies in individuals working in mines. The inclusion of middle ear assessment will contribute to early detection and intervention of middle ear pathologies, thus potentially increasing the quality of life.

\section{Acknowledgements}

The author wishes to thank Prof. Katijah Khoza-Shangase, his $\mathrm{PhD}$ supervisor, for the support during the writing of this article.

\section{Competing interests}

The author declares that he has no financial or personal relationships that may have inappropriately influenced him in writing this article.

\section{Author's contributions}

B.S. is the sole author of this research article.

\section{Funding information}

The author thanks the National Institute for the Humanities and Social Sciences (NIHSS) and the Consortium for Advanced Research Training in Africa (CARTA) for providing financial assistance for the publication of this manuscript.

\section{Data availability statement}

Data sharing is not applicable to this article as no new data were created or analysed in this study.

\section{Disclaimer}

The views and opinions expressed in this article are those of the author and do not necessarily reflect the official policy or position of any affiliated agency of the author.

\section{References}

Amedofu, G.K. (2002). Hearing-impairment among workers in a surface gold mining company in Ghana. African Journal of Health Science, 9, 91-97.

Anderson, S., Parbery-Clark, White-Schwoch, T., Drehobl, S., \& Kraus, N. (2013). Effects of hearing loss on the subcortical representation of speech cues. Journal of Acoustical Society of America, 133(5), 3030-3038. https://doi.org/10. $1121 / 1.4799804$

Baltazar, C.S., Horth, R., Inguane, C., Sathane, I., César, F., ... Young, P.W. (2015). HIV Prevalence and Risk Behaviours Among Mozambicans Working in South African

Cawood, F.T. (2011). Threats to the South African Minerals sectors - An independen view on the investment environment for mining. The Journal of the South African Institute of Mining and Metallurgy, 111(7), 469-474.

Chadambuka, A., Mususa, F., \& Muteti, S. (2013). Prevalence of noise induced hearing loss among employees at a mining industry in Zimbabwe. African Health Science, 13(4), 899-906. https://doi.org/10.4314/ahs.v13i4.6
Delrue, S., Verhaert, N., Van Dinther, J., Zarowski, A., Somers, T., Desloovere, C., \& Offeciers, E. (2016). Surgical management and hearing outcome of traumatic ossicular injuries. The Journal of International Advanced Otology, 12(3), 231-236. https://doi.org/10.5152/iao.2016.2868

Djulbegovic, M., Beyth, R.J., Neberger, M.M., Stoffs, T.L., Vieweg, J., Djulbegovic, B., Dahm, P. (2010). Screening for prostate cancer: Systematic review and metaanalysis of randomised controlled trials. British Medical Journal, 341, c4543. https://doi.org/10.1136/bmj.c4543

Donoghue, A.M. (2004). Occupational health hazards in mining: An overview. Occupational Medicine, 54(5), 283-289. https://doi.org/10.1093/occmed/ kqh072

Ensink, R.J.H., \& Kuper, H. (2017). Is hearing impairment associated with HIV? A systematic review of data from low- and middle-income countries. Tropical Medicine and International Health, 22(12), 1493-1504. https://doi.org/10.1111/ tmi.12993

Hermanus, M.A. (2007). Occupational health and safety in mining - Status, new developments and concerns. The Journal of the South African Institute of Mining and Metallurgy, 107(8), 531-538.

Higgins, J.P.T., \& Altman, D.G. (2011). The Cochrane collaboration's tool for assessing risk of bias in randomised trails: Research method \& reporting. British Medical Journal, 343, 1-9. https://doi.org/10.1136/bmj.d5928

Holman, J.A., Drummond, A., Hughes, S.E., \& Naylor, G. (2019). Hearing impairment and daily-life fatigue: A qualitative study. International Journal of Audiology, 58(7), 408-416. https://doi.org/10.1080/14992027.2019.1597284

Kanji, A., Khoza-Shangase, K., \& Ntlhakana, L. (2019). Noise-induced hearing loss: What South African mineworkers know. International Journal of Occupational Safety and Ergonomics, 25(2), 305-310. https://doi.org/10.1080/10803548.2017. 1412122

Kolo, E.S., Salisu, A.D., Yaro, A.M., \& Nwaorgu, O.G.B. (2012). Sensorineural hearing loss in patients with chronic suppurative otitis media. Indian Journal of Otolaryngology Head and Neck Surgery, 64(1), 59-62. https://doi.org/10.1007/ Otolaryngology Head
s12070-011-0251-5

Landen, D., Wilkins, S., Stephenson, M., \& McWilliams, L. (2004). Noise Exposure and Hearing Loss Among Sand and Gravel Miners. Journal of Occupational and Environmental Hygiene, 1(18), 532-541.

Margolis, R.H., \& Shanks, J. (1985). Tympanometry. In J. Katz (Ed.), Handbook of Clinical Audiology (pp. 438-475). Baltimore: Williams and Wikens.

Martins-Fonteyn, M., Loquiha, O., Baltazar, C., Thapa, S., Boothe, M., ... Wouters, E. (2017). Factors influencing risky sexual behaviour among Mozambican miners: A socio-epidemiological contribution for HIV prevention framework in Mozambique. International Journal for Equity in Health, 16, a179. https://doi.org/10.1186/ s12939-017-0674-z

Matas, C.G., Angrisani, R.G., Magliaro, F.C.L., \& Segurado, A.A.C. (2014). Audiological manifestations in HIV-positive adults. Clinics, 69(7), 469-475. https://doi.org/ 10.6061/clinics/2014(07)05

Moher, D., Liberati, A., Tetzlaff, J., \& Altman, D.G. (2009). Preferred reporting items for systematic reviews and meta-analysis: The PRISMA statement. BMJ, 2009(339), b2535. https://doi.org/10.1136/bmj.b2535

Moroe, N., \& Khoza-Shangase, K. (2018). Management of occupational noise induced hearing loss in the mining sector in South Africa: Where are the audiologists? Journal of Occupational Health, 60(5), 376-382. https://doi.org/10.1539/joh. 2018-0020-OA

Moroe, N., Khoza-Shangase, K., Kanji, A., \& Ntlhakana, L. (2018). The management of occupational noise-induced hearing loss in the mining sector in Africa: A systematic review - 1994 to 2016. Noise \& Vibration Worldwide, 49(5), 181-190. https://doi.org/10.1177/0957456518781860

Møller, A.R. (2006). Hearing: Anatomy, physiology, and disorders of the auditory system (2nd edn.). San Diego, CA: Academic Press.

Musiba, Z. (2015). The prevalence of noise-induced hearing loss among Tanzanian miners. Occupational Medicine, 65(5), 386-390. https://doi.org/10.1093/ occmed/kqv046

Obasineke, G., Amdi, F.I., Ibekwe, T.S., Ezeanolue, B.C., \& Ogisi, F.O. (2014). The effect of CD4 count level on the middle ear dynamics of HIV infected patients. East African Medical Journal, 91(1), 29-32.

Saunders, J.E., Jastrzembski, B.G., Buckey, J.C., Enriquez, D., Mackenzie, T.A., \& Karagas, M.R. (2013). Hearing Loss and Heavy Metal toxicity in a Nicaraguan Mining Community; Audiological Results and Case Reports. Audiology Neurotology, 18, 101-113. https://doi.org/10.1159/000345470

Sebothoma, B., \& Khoza-Shangase, K. (2018). A comparison between video-otoscopy and standard tympanometry findings in adults living with HIV in South Africa. South African Journal of Communication Disorders, 65(1), 1-7. https://doi.org/ 10.4102/sajcd.v65i1.591

Sharma, N., Jaiswal, A.A., Banerjee, P.K., \& Garg, A.K. (2015). Complications of chronic suppurative otitis media and their management: A single institution 12 years experience. Indian Journal of Otolaryngology and Head Neck Surgery, 67(4) 353-360. https://doi.org/10.1007/s12070-015-0836-5

Sogebi, O.A., Oyewole, E.A., \& Mabifah, T.O. (2018). Traumatic tympanic membrane perforation: Characteristics and factors affecting outcome. Retrieved from https:// www.ncbi.nlm.nih.gov/pmc/articles/PMC6026949/pdf/GMJ5201-0034.pdf

Tshifularo, M., Govender, L., \& Monama, G. (2013). Otolaryngological and head and neck manifestations in HIV-infected patients seen at Steve Biko Academic Hospital in Pretoria, South Africa. The South African Medical Journal, 10(7), 464-466. https://doi.org/10.7196/SAMJ.6786

Tuan, T.V. (2010). Meaning of sex, concepts of risk and sexual practices among migrant coal miners in Quang Ninh, Vietnam. Culture, Health Sexuality, 12(S1), S31-S40. 
Van der Westhuizen, Y., Swanepoel, D.W., Heinze, B., \& Hofmeyr, L.M. (2013). Auditory and otological manifestation in adults with HIV/AIDS. International Journal of Audiology, 52(1), 37-43. https://doi.org/10.3109/14992027.2012.721935

Vajpayee, M., Negi, N., \& Kurapati, S. (2013). The enduring tale of T cells in HIV immunopathogenesis. Indian Journal of Medical Research, 138(5), 682-699.

Villa, P.C., Zanchetta, S. (2014). Auditory temporal abilities in children with history of recurrent otitis media in the fisrt years of life and persistent in preschool and schoo ages. Communication Disorders, Audiology and Swallowing, 26(6), 494-502.
Vouloumanou, E.K., Karageorgopoulos, D.E., Kazantzi, M.S., Kapaskelis, A.M., Falagas, M.E. (2009). Antibiotics versus placebo or watchful waiting for acute otitis media: A meta-analysis of randomized controlled trials. Journal of antimicrobial A meta-analysis of rand

World Health Organization. (2018). Addressing the rising prevalence of hearing loss. Retrieved August 06, 2019 from https://apps.who.int/iris/bitstream/handle/ 10665/260336/9789241550260-eng. pdf;jsessionid=997DBEF8D9509748EEB7AB 8 C65581929?sequence $=1$ 